Article

\title{
Creativity and Emotions: A Descriptive Study of the Relationships between Creative Attitudes and Emotional Competencies of Primary School Students
}

\author{
Carmen M. Hernández-Jorge ${ }^{1, *(\mathbb{D})}$, Antonio F. Rodríguez-Hernández ${ }^{1}{ }^{(\mathbb{D}}$, Olena Kostiv ${ }^{1} \mathbb{C}^{\mathbb{D}}$, \\ Pilar B. Gil-Frías ${ }^{2}{ }^{(\mathbb{B}}$, Raquel Domínguez Medina ${ }^{1}$ and Francisco Rivero ${ }^{3}{ }^{(1)}$ \\ 1 Department of Evolutionary and Educational Psychology, University of La Laguna, 38205 La Laguna, Spain; \\ antrodri@ull.edu.es (A.F.R.-H.); olenakst@gmail.com (O.K.); radomm@ull.edu.es (R.D.M.) \\ 2 Department of Specific Didactics, University of La Laguna, 38205 La Laguna, Spain; pgilfria@ull.es \\ 3 Department of Clinical Psychology, Psychobiology and Methodology, University of La Laguna, \\ 38205 La Laguna, Spain; friverop@ull.es \\ * Correspondence: cherjo@ull.edu.es
}

Received: 19 May 2020; Accepted: 10 June 2020; Published: 11 June 2020

\begin{abstract}
This article presents the results of an exploratory study on the relationships between the emotional competencies and attitudes towards creativity in a sample of primary school students. This study is part of a wider project on the implementation of the curricular area "Emotional Education and Creativity," a far-reaching innovation in the educational system of the Canary Islands, Spain. A validated questionnaire for the evaluation of emotional and creative variables from the teachers' perspectives was used. The questionnaire was given to 230 primary school teachers, who used it to assess the emotional and creative competencies of 2540 schoolchildren. A bivariate correlation was carried out to establish the relationship between these competencies, and a multiple regression analysis was used to understand the influence of emotional skills on creativity. The results obtained confirmed the close relationship between the emotional dimension and the creative construct. Specifically, it was observed that emotional awareness was the competence with the closest relationship, together with the responsibility for one's own emotions, and the one that had the greatest weight in explaining creative competences. This result emphasizes that emotional and creative competencies complement each other and highlights the importance of working on these competencies together. We are committed to continuing with this line of research that supports an emotional conception of creativity.
\end{abstract}

Keywords: evaluation; creativity; emotional education; emotional creativity

\section{Introduction}

With the emergence in the late 1980s of theoretical models broadening our understanding of human intelligence, the door was opened to the systematic investigation of the "soft" dimensions of psychological performance-yet, as if it were a pendulum effect, we shifted from the exclusive study of the cognitive to the exclusion of all that was not affective. We consider that evidence of this polarization is evident in the field of neuroscience. There is a contradiction that even though the assumption of the interdependence between thinking and feeling is defended, at the level of research design, with few exceptions, the study of emotional functioning continues to be dissociated from cognitive processes because they are considered confounding variables.

Our study seeks to establish an empirical bridge between emotional competencies and our predisposition to being creative. It is part of a broader project that aims to evaluate the effects that the implementation of the curricular area of Emotional and Creativity Education (EMOCREA) has had on the educational community. 
This subject is taught in schools in the Canary Islands from the first to fourth year of Primary Education within the framework of the flexible curricular configuration by Spanish Autonomous Regions, as provided for in the Spanish Education Act (LOMCE) [1]. EMOCREA focuses on the development of learning skills, such as emotional awareness, regulation of emotions, and development of creativity [2]. In our opinion, this is an educational milestone of great relevance at regional, national, and international levels, since there are few precedents in the European context, and none in Spain, for the formal implementation of a curricular area that addresses the acquisition of emotional and creative competencies [3]. In this way, our proposal is based on an educational-competent vision of emotionality; it is based on the idea that the effective management of our emotions can and should be learned. This general competence would be translated into a series of specific emotional competences, such as: awareness, regulation, recycling, and creativity. Thus, when we use the concept of emotional competence, we are referring to the coherent integration of a set of knowledge, capacities, procedures, skills, and attitudes that make it possible for people to effectively manage their emotional world, both in relation to themselves and to others [4].

Why integrate the emotional education and creative development of students in the same subject? Based on our theoretical proposal, there is a close relationship between emotional competencies and creative capacity, which justifies treating them together in the training aspects that are being demanded from international organizations to face the new challenges presented by current and future contexts [4].

Since the middle of the last century, psychology has promoted the transition of our understanding from the paradigm of exceptionality - that is, "only the chosen ones can be creative" - to that of potentiality —or "we are all potentially creative" - depending on the facilitating or hindering contextual conditions we experience $[5,6]$.

In this effort to locate creative potential, the psychometric models of creativity assessment have focused on the cognitive dimension, identifying creativity with divergent thinking. However, in a parallel way, it has been considered that this essentially human quality entails a non-cognitive, attitudinal, and even affective dimension, which is related to the way in which people consider themselves as creative subjects.

This complementary cognitive-affective vision is at the core of the differentiation between "creativity" and "creativeness" that is used when referring to the concept of creativity. It is precisely the second term that connects with our proposal for evaluating the creative construct.

This tendency to divorce the aptitudinal from the attitudinal probably comes from the rationalist conception of understanding affection as a contaminant that conditions and harms creative thinking. However, scientific evidence contradicts this, given that non-cognitive aspects play an important role as motivational factors in creativity, especially when it comes to facilitating, inhibiting, or guiding creativity [7].

In our case, this relationship is connected to the tradition of assessing creative personalities [8], which has been instrumentally translated into sets of tests and inventories that aim to isolate the attitudes, interests, perceptive trends, traits, biographical experiences, values, and characteristics of creative individuals.

Ruíz-Melero et al. provide a review of works that establish the current relevance of this line of research into the creative personality [9], centered on the studies of Selby et al. [10]. This review gives examples of studies that have attempted to isolate the personal characteristics that define the most creative people [11-13]. The study also provides an updated overview of the work relating the big five personality factor model of Costa and McCrae [14] with the creative construct. The studies reviewed indicate that the trait of openness to experience characterizes the most creative people; therefore, people open to new experiences and, with greater independence of judgment, manifest themselves as more creative [15-18], although other studies highlight that the awareness/responsibility factor (ability to control impulses and to organize and plan the tasks or activities to be performed) is also associated with creativity $[9,12,17,19]$. 
Related to the above lines of research, Baas et al. have studied the relationship between full attention skills and creativity, finding that observation is the variable that best predicts creativity [20]. They consider that this skill is more related to openness to experience [21], which, as we have indicated above, is a personality trait among the strongest predictors of creativity [22]. In addition, we must consider the skills involved in full attention. Observation implies the ability to collect relevant information from the internal and external world [23], which would connect with one of the attitudinal dimensions of creativity, such as sensitivity to reality.

Moreover, several investigations have supported the two-way framework of creativity, understanding cognition and individual traits as interrelated components [22,24,25]. Specifically, trait creativity is related to persistence, self-confidence, willingness to take risks, impulsiveness, ambition, doubt, and imagination [26-28].

Our study proposes the isolation of precisely these subjective components of the personal dimension of creativity by focusing on three aspects: the confidence that subjects manifest when facing obstacles that limit the expression of their creativity (creative self-confidence), the sensitivity that they manifest to being open to the stimuli of their environment and to questioning them (openness to change and innovation), and, finally, their predisposition to take the initiative, to lead, and to formulate proposals to others in order to develop collective projects (vital entrepreneurship).

On the specific level of the relationship between emotional intelligence (EI) and creativity, George and Zhou discovered that clarity of feeling is positively associated with creative performance [29]. This indicates that emotional awareness favours divergent production.

It should be noted that studies aiming to link EI and creativity have obtained conflicting results. Some that provide measures for creative personalities confirm the hypothesis that high EI trait is associated with high creativity. However, research introducing divergent thinking tasks does not support these results: the correlations between EI and divergent thinking scores are weak and not significant $[30,31]$.

The papers reviewed insist on taking into consideration the role that emotional competencies play in the creative process, as it enables people to meet the challenges of creative work. Some of these challenges consist of finding and solving problems and generating original ideas, despite experiencing limiting emotions and obstacles [32]. These emotional competencies are also necessary to transform emotions as motivators towards creative activity.

The close relationship between problem solving and creativity has been a constant theme in psychometric studies [33] and, in particular, the ability to analyze the causes of a problem. Sanchez et al. points out that divergent causal production would influence problem solving through the flexibility factor [34], since flexibility implies, among other things, the ability to look at problems from various points of view [35].

Moreover, creativity can be enhanced with proper awareness and emotional management. In this sense, Cohen and Andrade showed that some people are able to match their emotional state with tasks that would benefit from emotionality for better results [36]. According to the theory of emotional intelligence, emotional facilitation, among other things, allows feelings to be taken into consideration when a person reasons or solves problems. Thus, the perspective of a problem changes depending on our emotional state and creative thinking can be improved [37].

Studying the concept of creativity within the field of neuroscience, the research carried out by Zhuang et al. using neuroimaging is worth noting; they found relationships between trait creativity in 9 to 12-year-old children and emotion-related regions within the limbic system, which can be interpreted as being emotion-dominant [38]. Specifically, the amygdala and hippocampus were linked to traits of challenge and risk taking, while the orbitofrontal cortex was linked to imagination. These regions are fundamental as motivators to influence creativity from emotional aspects.

Finally, there is the proposal by Ivcevic et al. about what they call emotional creativity [31]. This refers to the ability to experience and express a mixture of emotions in new and effective ways. It introduces three criteria in its definition: the first two closely related to those that characterize 
divergent production (originality and effectiveness) and the third, honest emotional communication (authenticity), to which the condition of emotional preparation related to the understanding of emotions and the willingness to explore them must be added.

What is interesting about the contribution of these authors is the parallelism they establish between emotional intelligence (EI) and emotional creativity (EC) with cognitive intelligence and divergent thinking. Thus, while EI manifests itself in the analytical capacity and convergence to choose a competent response to an emotional problem, EC involves the ability to diverge from the norm and generate a novel emotional reaction [31].

The results of their studies indicated that EI and EC are two constructs made up of different skills. Correlations and confirmatory factor analyses supported this hypothesis. Furthermore, self-reported measures of EC significantly correlated with laboratory measures, while measures of EC ability only correlated with self-reported artistic activity. EI was not correlated with creative behavior. The data they found on the relationship between openness to experience and understanding of emotions is of special interest to our work [31].

Kuška et al. offer a meta-analysis, in which the results of studies that have applied the Emotional Creativity Inventory (ECI) are collected $[39,40]$. In this systematic review, the close relationship between emotional creativity and other variables, such as openness to experience, is confirmed [41], as we have already indicated. At the same time, they point out the negative relationship with emotional deficits, such as alexithymia and apathy $[42,43]$.

Moreover, significant gender differences are found in emotional creativity. Higher total scores in the three ECI subscales in women more than in men have been identified $[18,39]$. It is also worth noting that EC is a positive modulator for the development of various skills, abilities, and dispositions, such as: effectiveness of teaching, self-understanding, awareness of professional roles, innovative performance, and intrinsic employee motivation [39].

What, then, would be the conditions that favor emotional creativity? Moltafet et al. believe that a supportive environment, which helps people to meet their needs for autonomy and competence, makes it easier for us to feel creatively [44]. Likewise, it has been discovered that emotional creativity and its dimensions are related to emotions, such as gratitude, hope, love, pride, inspiration, interest, and fun, functioning as mediating effects between creative feeling and intrinsic motivation, on the one hand, and academic commitment, on the other $[45,46]$.

Additionally, from the perspective of the emotions that link us to others, it has been highlighted that the traits of emotional intelligence and creativity seem to be related only when emotionality and sociability are considered. This indicates that the characteristics that can help individuals to understand the emotions of others can influence their judgments in order to value an achievement as creative [46].

The approach we propose in this study has nothing to do with artistic creativity, but with vital creativity, with the exclusively human potential to create and recreate their own conditions of existence and, above all, to apply creative experiences (ideas, feelings, motivations, and behaviors) that help to improve their personal and collective well-being to everyday life.

In this sense, we agree with the issues raised by Ivcevic et al. [31]. Not only do we think creatively (divergent thinking), we can also feel creatively (divergent affectivity) [5,47], insofar as, in order to be creative, one must not only believe it, but, fundamentally, feel it: feel creative. It is here where creativity and emotionality "cross on the path" of human experience.

The main objectives of our research are: (a) to analyze the relationship between the emotional and creative competencies of school children according to their teachers' assessments; and (b) to determine what weight emotional competencies have in creative competencies.

More specifically, we attempt to analyze the influence of factors related to emotional competencies on attitudinal creativity through multivariate methods. In addition, we observe the relationships between the items in the assessment instrument used to discover how specific emotional competencies behave, and how much they influence the components of attitudinal creativity. 


\section{Materials and Method}

\subsection{Participants}

Participants in the study were obtained through Primary Education teachers whose schools were participating in the project "Evaluation and Monitoring of the area of Emotional and Creativity Education (EMOCREA)" established by the Canary Island Region of Spain in the 2015-2016 and 2016-2017 school years.

The study involved 230 Primary Education teachers, who assessed 2540 schoolchildren in the 2015-2016 and 2016-2017 school years. They belonged to 25 public schools in six of the eight Canary Islands (the islands of La Gomera and La Graciosa did not participate), in which the EMOCREA area was taught by a teacher from the center, who also taught another subject area (63.3) or by the tutor of the group of schoolchildren (34.7\%) (see Table 1).

Table 1. Data of the Samples Participating in the Study.

\begin{tabular}{cccc}
\hline Teachers & Students & Tutors & Teachers from other Areas \\
\hline 230 & 2540 & $34.7 \%$ & $63.3 \%$ \\
\hline
\end{tabular}

\subsection{Instruments}

The instrument used was the Emotional Awareness and Creativity Questionnaire for primary school teachers (D-ECREA). It was based on the evaluation criteria set out in the curriculum of the subject prepared by the Department of Education of the Canary Islands Autonomous Government [2]. These criteria were: emotional perception, emotional recognition, emotional understanding, emotional regulation, emotional responsibility, self-confidence, openness to change, and innovation and entrepreneurship. A sentence was established for each of these criteria together with examples of each one of them. Two criteria were taken into account in developing the questionnaire. The first one was that the questionnaire should be adapted to the way of evaluating any other subject area, and the second one was to make it short and simple to fill in, since both aspects would favor the use of the instrument by the teachers. Once the questionnaire was constructed, it was presented to teachers by their centers or through meetings in teaching training centers (CEPs) so that they could get to know it, assess it, and become familiar with its use and operation.

The questionnaire consisted of eight sentences — one for each evaluation criterion of the EMOCREA subject indicated in the curriculum — of which, five corresponded to emotional aspects (three on emotional awareness and two on emotional regulation) and three to the development of creativity. In the questionnaire format, the name of the emotional competence, its description, and a representative example that served as a reference for its evaluation were presented. An English translation of this questionnaire is included in the Appendix A.

The form of response is a Likert type scale from 0 to $3(0=$ never, $3=$ always), by means of which the acquisition of each of the competences in the variables of the questionnaire and by each of the schoolchildren was assessed. The variables collected were based on the Rodríguez model [4] (p. 46), to which creativity was added, adapting to the curriculum developed by the Autonomous Government of the Canary Islands [2].

Emotional Awareness Block:

- Emotional perception. Awareness of the bodily sensations that are associated with emotional experiences.

- Emotional recognition. Identifying one's own emotions and those of others and accepting them without dissociating oneself from them.

- Emotional understanding. Understanding and analyzing the emotions you experience, their relationship with what has happened before, and their consequences. 
Emotional Regulation Block:

- Emotional regulation. Regulating the experience and emotional expression through reflexivity, tolerance to frustration, and overcoming difficulties. In short, the self-regulation of emotional impulsivity.

- Emotional responsibility. Accepting responsibility for one's own behavior, for the consequences of what one feels, for the damage that can be done to oneself, and to others with the behavior derived from one's emotions.

\section{Creativity Block}

- Self-confidence. Self-confidence in the face of obstacles to your creativity.

- Openness to change and innovation. Sensitivity to reality and interrogative capacity.

- Entrepreneurship. Capacity to have initiative and projects

The questionnaire has proven to be robust, in that its theoretical structure (emotional awareness, emotional regulation, and creativity) has been confirmed. The confirmation of the factorial structure has been obtained in different samples-specifically, in a total sample made up of 230 Primary Education teachers, who assessed 2540 schoolchildren in the 2015-2016 and 2016-2017 school years, and in three sub-samples. There have also been previous measurements made in the 2015-2016 school year by 154 primary school teachers, who assessed 1156 students. This sub-sample repeated the assessment five months later, assessing the same students. Finally, a third subsample was made up of 76 primary school teachers, who assessed 1369 students in the 2016-2017 school year. In total, they belonged to 25 centers in six of the eight Canary Islands (the islands of La Gomera and La Graciosa did not participate).

The Kaiser-Meyer-Olkin index (KMO) obtained in each of these samples was higher than $0.83(p \leq 0.05)$, obtaining high internal consistency calculated from Cronbach's alpha, which, in all components in each of the subsamples, was higher than 0.70 and did not increase in any case by the elimination of any item.

In addition, it was observed that the instrument was sensitive to measuring the change in the emotional competencies of schoolchildren, which we verified by means of a mixed ANOVA $4 \times 2$ (Level $\times$ Moment) on the components. In this respect, we observed how there was an increase in the perception of emotional competencies in different years (from first to fourth year) before and after teaching the EMOCREA subject in the 2015-2016 school year.

\subsection{Procedure}

Regarding the ethical aspects of our work, we must emphasize that our study did not involve experimental manipulation, since it was a collection of data for evaluation. To do this, we obtained the authorization of the centers within the framework of the agreement of our research team with the educational authorities. In addition, the treatment of the data complied with the principle of confidentiality, respecting the right to anonymity of the centers and the subjects who participated in the study.

The questionnaires were distributed to the educational centers through the figure of teaching advisors from teacher training centers on the Canary Islands (CEP). They were given to the teachers with sufficient time to fill them in and return them, so that the research team could analyze them before the first evaluation of the centers. Teachers were offered a final result for each school, so that, before the exam period, they had a score representative of the emotional competencies of his or her students. It was at the teacher's discretion to use it to establish the final grade of the term or to combine it with other evaluative aspects of the teaching-learning process that he or she established. The data obtained were included in an Excel template for subsequent inclusion in the SPSS statistical program database and the corresponding data analysis. 


\subsection{Data Analysis Design}

To respond to the objectives and research questions in this study, a correlation design was developed using two specific analytical techniques. First, an analysis of bivariate correlations between the study variables was carried out, and, second, a multiple regression analysis was performed to observe the influence of the different variables on the criterion variable of creativity. All this was done with the SPSS v25 statistical package.

\section{Results}

\subsection{Analysis of the Main Components}

Table 2 shows that the average scores of the different components of the questionnaire were between 2.08 and 2.35. Emotional awareness was the component with the highest average score $(\bar{X}=2.35 ;$ Sx $=0.607)$, followed by emotional regulation $(\bar{X}=2.16 ; S x=0.727)$, and, finally, creativity $(\bar{X}$ $=2.08 ; \mathrm{Sx}=0.645)$.

Table 2. Descriptive Analysis.

\begin{tabular}{ccc}
\hline & Average & Standard Deviation \\
\hline Emotional Awareness & 2.35 & 0.607 \\
Emotional Regulation & 2.16 & 0.727 \\
Creativity & 2.08 & 0.645 \\
\hline
\end{tabular}

Table 3 shows that there were high and, above all, significant correlations between the components of the questionnaire. The highest correlation was established between emotional awareness and creativity $(0.581 ; p \leq 0.001)$ and a much lower one between emotional regulation and creativity $(0.359$; $p \leq 0.001)$. As expected, there were also significant correlations between the components of awareness and emotional regulation (0.494; $p \leq 0.001)$.

Table 3. Bivariate Correlations between the Main Components.

\begin{tabular}{cccc}
\hline & & Creativity & Emotional Awareness \\
\hline \multirow{2}{*}{ Emotional Awareness } & Pearson Correlation & $0.581^{* *}$ & \\
& Sig. (bilateral) & 0.000 & $0.494^{* *}$ \\
\multirow{2}{*}{ Emotional Regulation } & Pearson Correlation & $0.359^{* *}$ & 0.000 \\
\hline
\end{tabular}

Note: ${ }^{* *} p \leq 0.001$.

We also wanted to determine the influence that emotional aspects had on creativity. The multiple factor regression analysis gave us the results shown in Table 4. Firstly, it is important to point out that the model was plausible and explained more than $60 \%$ of the variance (AdjR $2=0.344 ; p \leq 0.001$ ). Secondly, we can state that the components related to emotional aspects predicted creativity with a significance of $p \leq 0.001$, and, observing the model, it seemed that emotional awareness had greater predictive power $(0.534 ; p \leq 0.001)$ than emotional regulation $(0.096 ; p \leq 0.001)$.

Table 4. Multiple Regression of Emotional Awareness and Emotional Regulation with Respect to Creativity.

\begin{tabular}{lccc}
\hline & Creativity & AdjR $^{2}$ & Significance \\
\hline & $\mathrm{B}$ & 0.344 & 0.000 \\
Emotional Awareness & 0.534 & & 0.000 \\
Emotional Regulation & 0.096 & & 0.000 \\
\hline
\end{tabular}




\subsection{Analysis of the Questionnaire Items}

Based on these results, the next step was to identify the relationships between the items in the questionnaire to observe how they behaved and what they contributed to creative aspects. We observed that there were correlations between the items that collated emotional aspects (see Table 5). Thus, the physiological perception of emotions was strongly related to their recognition $\left(0.551^{* *}\right)$ and understanding $\left(0.516^{* *}\right)$. At the same time, it seemed that recognizing one's own emotions was related to understanding them $\left(0.628^{* *}\right)$ and to responsibility for them $\left(0.407^{* *}\right)$. In addition, understanding emotions was related to emotional regulation $\left(0.433^{* *}\right)$ and to the responsibility for one's own emotions $\left(0.419^{* *}\right)$. Regulating emotions was related to responsibility for them $\left(0.623^{* *}\right)$. Regarding the aspects that make up creativity, self-confidence in creative abilities was related to openness $\left(0.501^{* *}\right)$ and to an entrepreneurial attitude $\left(0.485^{* *}\right)$, while the latter was related to openness $\left(0.550^{* *}\right)$. Finally, relationships were established between emotional aspects and creative aspects. In this sense, recognizing one's own emotions and understanding them was related to self-confidence in creative capacities $\left(0.456^{* *} ; 0.473^{* *}\right.$, respectively), to openness $\left(0.386^{* *}, 0.407^{* *}\right)$, and to the capacity for entrepreneurship $\left(0.383^{* *} ; 0.444^{* *}\right)$.

Table 5. Correlations between Questionnaire Items.

\begin{tabular}{|c|c|c|c|c|c|c|c|}
\hline & 1 & 2 & 3 & 4 & 5 & 6 & 7 \\
\hline 1 & & & & & & & \\
\hline 2 & $0.551^{* *}$ & & & & & & \\
\hline 3 & $0.516^{* *}$ & $0.628^{* *}$ & & & & & \\
\hline 4 & $0.282 *$ & $0.399 * *$ & $0.433^{* *}$ & & & & \\
\hline 5 & $0.316^{* *}$ & $0.407^{* *}$ & 0.419 ** & 0.623 ** & & & \\
\hline 6 & $0.374^{* *}$ & $0.456^{* *}$ & $0.473^{* *}$ & $0.283^{* *}$ & $0.303^{* *}$ & & \\
\hline 7 & $0.382^{* *}$ & $0.386^{* *}$ & $0.407^{* *}$ & $0.254^{* *}$ & $0.270^{* *}$ & $0.501^{* *}$ & \\
\hline 8 & $0.306^{* *}$ & $0.383^{* *}$ & $0.444^{* *}$ & $0.245^{* *}$ & $0.234^{* *}$ & $0.485^{* *}$ & $0.550 * *$ \\
\hline
\end{tabular}

It is also important to observe the influence of each of the emotional aspects (items of the questionnaire) on each of the ones that measure creativity. Table 6 shows the predictive capacity of each emotional aspect with respect to personal self-confidence about one's creative skills. It shows that the model was plausible and explained more than $50 \%$ of the variance ( $\operatorname{Adj}^{2}=0.277 ; p \leq 0.001$ ). It also points out that the components related to aspects of emotional awareness (perception, recognition, and understanding of emotions) predicted self-confidence with a significance of $p \leq 0.001$, while emotional recognition predicted it with a lower level of significance $(p \leq 0.01)$ and the regulation of emotions had no predictive power. Entering into detail, it was observed that emotional understanding had the greatest predictive power $(0.296 ; p \leq 0.001)$, followed by emotional recognition $(0.234 ; p \leq 0.001)$, emotional perception $(0.114 ; p \leq 0.001)$, and emotional responsibility, which had a residual power in predicting self-confidence $(0.067 ; p \leq 0.05)$.

Table 6. Multiple Regression of each aspect of Emotional Awareness with respect to Self-Confidence.

\begin{tabular}{cccc}
\hline & B & Adj $^{2}$ & Significance \\
\hline Emotional Perception & 0.114 & 0.277 & 0.000 \\
Emotional Recognition & 0.234 & & 0.000 \\
Emotional & 0.296 & & 0.000 \\
Understanding & 0.022 & & 0.000 \\
Emotional Regulation & 0.067 & 0.326 \\
Emotional Responsibility & & 0.003 \\
\hline
\end{tabular}


Table 7 shows the predictive capacity of each of the emotional aspects with respect to openness to experience. On this occasion, the model was also plausible, explaining more than $40 \%$ of the variance $\left(\operatorname{Adj} R^{2}=0.222 ; p \leq 0.001\right)$. At the same time, it was verified that the components related to emotional aspects predicted openness to experience with a significance of $p \leq 0.001$ in most cases, and $p \leq 0.05$. In this case, emotional understanding also had a greater predictive power $(0.205 ; p \leq 0.001)$ than emotional perception $(0.185 ; p \leq 0.001)$, emotional recognition $(0.132 ; p \leq 0.001)$, or responsibility over one's own emotions $(0.053 ; p \leq 0.05)$. In addition, emotional regulation did not have the capacity to predict openness to experience.

Table 7. Multiple Regression of each aspect of Emotional Consciousness with respect to Openness to Experience.

\begin{tabular}{cccc}
\hline & $\boldsymbol{\beta}$ & Adj $^{\mathbf{2}}$ & Significance \\
\hline & & 0.222 & 0.000 \\
Emotional Perception & 0.185 & & 0.000 \\
Emotional Recognition & 0.132 & & 0.000 \\
Emotional & 0.205 & & 0.000 \\
Understanding & 0.032 & & 0.132 \\
Emotional Regulation & 0.053 & & 0.014 \\
Emotional Responsibility & &
\end{tabular}

Finally, it seemed that the model was plausible, explaining more than $40 \%$ of the variance $\left(\operatorname{Adj} R^{2}=0.216 ; p \leq 0.001\right)$ and stating that the components related to emotional aspects predicted the entrepreneurship of school children, with a significance of $p \leq 0.001$. Here, too, emotional understanding had the greatest predictive power $(0.348 ; p \leq 0.001)$, followed by emotional recognition (0.158; $p \leq 0.001)$ and emotional perception $(0.061 ; p \leq 0.01)$. In this case, the aspects of emotional regulation and responsibility were not significant in explaining the capacity for entrepreneurship (see Table 8).

Table 8. Linear Regression of each aspect of Emotional Awareness with respect to Entrepreneurship.

\begin{tabular}{cccc}
\hline & $\boldsymbol{\beta}$ & Adj $^{2}$ & Significance \\
\hline & & 0.217 & 0.000 \\
Emotional Perception & 0.061 & & 0.008 \\
Emotional Recognition & 0.158 & & 0.000 \\
Emotional & 0.348 & & 0.000 \\
Understanding & 0.035 & & 0.128 \\
Emotional Regulation & 0.007 & & 0.776 \\
Emotional Responsibility & & \\
\hline
\end{tabular}

\section{Discussion}

Our research objectives were aimed, on the one hand, at analyzing the relationship between the emotional and creative competencies of schoolchildren according to their teachers, and, on the other hand, at finding out what weight emotional competencies have on creative competencies.

The first conclusion of our study is that, indeed, there seems to be a significant correlation between emotional and creative competencies. Above all, there is a stronger correlation between emotional awareness and creativity than between the regulation of emotions and creativity. We know in this respect that diverse studies highlight the relationship that exists between the personality factor awareness/responsibility with creativity $[9,12,17,19]$.

A more detailed analysis of the results leads us to the second conclusion that emotional awareness predicts the various aspects related to creativity much more than regulation or responsibility for these emotions. We consider that these last two components predict to a lesser extent the different components of creativity, because they are more convergent aspects, since they imply systematization, certain regulation, and aspects of self-control, which contrast with creative aspects, which are more divergent. 
A third conclusion is that the different items that constitute emotional awareness constitute a continuum of depth in consciousness that relates to creative divergence as it deepens. In this way, at the most superficial pole, emotional perception would be found. At an intermediate stage, recognition would be situated, and at the pole of greatest depth, and, therefore, the most divergent, emotional understanding would be present.

It should be noted that emotional perception does weigh on openness to experience, because they may be similar aspects. Perhaps a certain openness or sensory sensitivity could be hypothesized. On the one hand, to perceive emotions, it is necessary to make contact with one's own bodily sensations, which can also be related to openness to the perception of stimuli in general (internal or external), which is necessary to have openness to the experience. As Carson and Langer also point out, there is an explicit need for the capacity to gather relevant information from the internal and external world [23].

However, if there is one variable that has the greatest predictive value for the tendency to feel creative, it is emotional understanding. This competence, defined by the ability to analyze the causal-consequential trajectory of emotional experiences, is the one that best explains any of the evaluated components of the divergent attitude (creative self-confidence, sensitivity to reality, and vital entrepreneurship).

This result in our research is linked to those that have been found in other referenced studies. For example, George and Zhou found a connection between clarity of feeling (TMMS factor oriented to emotional understanding) and divergent performance [29]. There are also studies that have linked problem solving and the ability to analyze the causes of a problem [34].

In addition, Ivcevic et al., with their insightful proposal of the concept of emotional creativity, suggest that as well as the three criteria that define it (originality, effectiveness, and authenticity), the condition of emotional preparation related to understanding emotions must be added [31].

The main limitation of this study lies in the assessment method used. On the one hand, the use of a hetero-assessment questionnaire limits the focus on the object of study to a deferred assessment by the observer and to manifest aspects of the behavior [48]. On the other hand, by using trait measures of emotional intelligence and creative personality, the understanding between these variables is not approached from a more competent perspective in terms of the resolution of divergent thinking tasks and the practical execution of emotional management skills, so that the results may reflect a belief more than effective potential $[30,31,46]$.

Therefore, a line of continuity of this research should be oriented to complement the measures used with others of a self-assessment and competence nature to cover a $360^{\circ}$. understanding of the relationships between emotional competencies and creative potential.

Another aspect of our work to be improved has to do with the theoretical construct "emotional creativity." Our instrument collects the attitudinal dimension of creativity, focusing on aspects more related to divergent thinking. Therefore, in spite of contemplating affective aspects of creativity (self-confidence, sensitivity to reality, and entrepreneurship), it does not strictly address the affective-creative dimension in terms of the synthesis of cognitive skills and personality traits related to originality and the appropriateness in the emotional experience [31,39,40].

Therefore, another line of research would consist of dealing with the understanding of the links between emotional competencies and those aspects more directly related to emotional creativity in terms of the emotional experience of one's own creativity (feeling creative), the emotionality that facilitates and hinders creative development, and one's own capacity to experience emotions in a divergent way.

Despite these restrictions, this study represents an empirical demonstration of how competent emotionality can help people to develop their creative potential. This involves one of the essential aspects of our humanity, or, in other words, the strategic relationship between the cognitive and the affective, between reason and emotion.

Moreover, it is precisely the desire for schools to have a much wider role, not only from an individual's integral education perspective, but we should also aspire to develop ourselves beyond the 
exclusively intellectual, or, as humanists would say, "from the neck up," integrating. This is what we have attempted to do in the Canary Islands by including emotional competencies within the official curriculum. Moreover, this is of particular relevance given the complex reality that increasingly shows our vulnerability as a species. This requires taking two key elements of our capacity to overcome adversity in a resilient way into consideration: creativity and competent emotionality. Indeed, to paraphrase Albert Einstein, "if this society wants to survive, it needs another way of thinking" and, we would add, another way of feeling.

Author Contributions: Conceptualization, A.F.R.-H. and P.B.G.-F.; Data curation, C.M.H.-J. and F.R.; Formal analysis, C.M.H.-J. and F.R.; Investigation, A.F.R.-H.; Project administration, A.F.R.-H.; Supervision, C.M.H.-J., R.D.M. and F.R.; Writing—original draft, A.F.R.-H.; Writing—review \& editing, C.M.H.-J., O.K., P.B.G.-F., and R.D.M. All authors have read and agreed to the published version of the manuscript.

Funding: This study was carried out thanks to the financial support provided by Consejería de Educación, Universidades, Cultura y Deportes del Gobierno de Canarias. Spain.

Conflicts of Interest: The authors declare no conflict of interest.

\section{Appendix A. Teachers' Questionnaire}

\begin{tabular}{|c|c|c|c|c|}
\hline \multirow{2}{*}{ Emotional Self-Awareness } & Never & & & Always \\
\hline & 0 & 1 & 2 & 3 \\
\hline \multicolumn{5}{|l|}{$\begin{array}{l}\text { 1. Perception: She/he perceives the bodily sensations associated } \\
\text { with emotional experiences. }\end{array}$} \\
\hline \multicolumn{5}{|l|}{$\begin{array}{l}\text { 2. Recognition: She/he identifies her/his own emotions and those of } \\
\text { others and identifies the bodily signals of emotions in others. }\end{array}$} \\
\hline \multicolumn{5}{|l|}{$\begin{array}{l}\text { 3. Understanding: She/he understands and analyses the emotions } \\
\text { experienced and relates them to what has happened before and } \\
\text { with its consequences (why they feel this way, what happened } \\
\text { before and after). }\end{array}$} \\
\hline \multirow{2}{*}{ Emotional Regulation } & Never & & & Always \\
\hline & $\mathbf{0}$ & 1 & 2 & 3 \\
\hline $\begin{array}{l}\text { 4. She/he regulates experience and emotional expression through } \\
\text { reflexivity (think before you act), tolerance to frustration and } \\
\text { overcoming difficulties. Self-regulation of emotional impulsivity }\end{array}$ & & & & \\
\hline
\end{tabular}

5. Responsibility: She/he assumes responsibility for their own conduct. She/he takes responsibility for the consequences of what she/he feels, for the damage that she/he can do to herself/himself and to others with the behaviour derived from her/his emotions.

\begin{tabular}{|c|c|c|c|c|}
\hline \multirow{2}{*}{ Creativity } & \multicolumn{2}{|c|}{ Never } & & Always \\
\hline & 0 & 1 & 2 & 3 \\
\hline
\end{tabular}

7. Openness To Change And Innovation Sensitivity to reality and interrogative capacity

8. Entrepreneurship: Ability to have initiative and projects

Rate the following aspects from 0 to 3 so that 0 indicates that the competence never appears in the child and 3 indicates that the competence always appears in the child. 


\section{References}

1. Gobierno de España. Ley Orgánica 8/2013, Para La Mejora de La Calidad Educativa. Bol. Estado 2013, 295, 97858-97921.

2. Gobierno de Canarias. Decreto 89/2014. Bol. Canarias 2014, 156, 626-671.

3. Clouder, C.; Pedersen, C.S.; Cefai, C.; Madrazo, C.; Boland, N.; Antognazza, D.; Fernández-Berrocal, P. Educación Emocional y Social. Análisis Internacional; Fundación Botín: Santander, Spain, 2015; ISBN 978-84-15469-44-5.

4. Rodríguez, A. EducaEMOción; Santillana Educación: Madrid, Spain, 2018; pp. 39-88. ISBN 978-84-680-4348-7.

5. Rodríguez, A. Futuro y creatividad: Una mirada prospectivo-social sobre la creatividad. In Creatividad y Sociedad: Hacia Una Cultura Creativa en el Siglo XXI; Rodríguez, A., Pérez, G., López-Barajas, E., Eds.; Octaedro: Barcelona, Spain, 2001; pp. 29-60. ISBN 978-8480634786.

6. Rodríguez, A. La dimensión social de la creatividad. In La Creatividad. Un Bien Cultural de la Humanidad; Ferreiro Gravié, R., Mitjans Martinez, A., Montesino, L., Rodríguez, A., Waisburd, G., Romo Santos, M., Eds.; Trillas: Mexico City, Mexico, 2008; pp. 13-36. ISBN 978-968-24-8285-4.

7. Sanchez-Ruiz, M.J.; Hernández-Torrano, D. La compleja relación entre creatividad y afecto. Estud. Psicol. 2014, 35, 239-265. [CrossRef]

8. Alfonso Benlliure, V. Evaluación de la personalidad creativa. In Comprender y Evaluar la Creatividad; Dialnet: Valencia, Spain, 2006; Volume 2, pp. 303-323. ISBN 84-9700-324-1.

9. Ruiz-Melero, M.J.; Bermejo, R.; Ferrando, M.; Sainz, M. No solo la apertura define a los estudiantes con mayor potencial creativo. Electron. J. Res. Educ. Psychol. 2020, 18, 55-76. Available online: http: //ojs.ual.es/ojs/index.php/EJREP/article/view/2645/3447 (accessed on 18 May 2020).

10. Selby, E.C.; Shaw, E.J.; Houtz, J.C. The Creative Personality. Gift. Child. Q. 2005, 49, 300-314. [CrossRef]

11. Feist, G.J.; Barron, F.X. Predicting creativity from early to late adulthood: Intellect, potential, and personality. J. Res. Pers. 2003, 37, 62-88. [CrossRef]

12. Szobiová, E. The five personality dimensions in relation to creative thinking of adolescents. Stud. Psychol. 2006, 48, 241-249. Available online: https://www.studiapsychologica.com/index.php/view-articles/?search= Szobiov\%C3\%A1 (accessed on 18 May 2020).

13. McCrae, R.R.; Greenberg, D.M. Openness to experience. In The Wiley Handbook of Genius; John Wiley \& Sons, Ltd.: Chichester, UK, 2014; pp. 222-243. [CrossRef]

14. Costa, P.T.; McCrae, R.R. Normal personality assessment in clinical practice: The NEO personality inventory. Psychol. Assess. 1992, 4, 5-13. [CrossRef]

15. Wolfradt, U.; Pretz, J.E. Individual differences in creativity: Personality, story writing, and hobbies. Eur. J. Pers. 2001, 15, 297-310. [CrossRef]

16. Dollinger, S.J.; Urban, K.K.; James, T.A. Creativity and openness: Further validation of two creative product measures. Creat. Res. J. 2004, 16, 35-47. [CrossRef]

17. Ma, H.-H. The Effect size of variables associated with creativity: A meta-analysis. Creat. Res. J. 2009, $21,30-42$. [CrossRef]

18. Da Costa, S.; Páez, D.; Sánchez, F.; Garaigordobil, M.; Gondim, S. Personal factors of creativity: A second order meta-analysis. Rev. Psicol. Trab. Organ. 2015, 31, 165-173. [CrossRef]

19. Furnham, A. The bright and dark side correlates of creativity: Demographic, ability, personality traits and personality disorders associated with divergent thinking. Creat. Res. J. 2015, 27, 39-46. [CrossRef]

20. Baas, M.; Nevicka, B.; Ten Velden, F.S. Specific mindfulness skills differentially predict creative performance. Pers. Soc. Psychol. Bull. 2014, 40, 1092-1106. [CrossRef] [PubMed]

21. Baer, R.A.; Smith, G.T.; Hopkins, J.; Krietemeyer, J.; Toney, L. Using self-report assessment methods to explore facets of mindfulness. Assessment 2006, 13, 27-45. [CrossRef]

22. Baas, M.; Roskes, M.; Sligte, D.; Nijstad, B.A.; De Dreu, C.K.W. Personality and creativity: The dual pathway to creativity model and a research agenda. Soc. Pers. Psychol. Compass 2013, 7, 732-748. [CrossRef]

23. Carson, S.H.; Langer, E.J. Mindfulness and self-acceptance. J. Ration. Cogn. Ther. 2006, 24, 29-43. [CrossRef]

24. Silvia, P.J.; Christensen, A.P.; Cotter, K.N. Commentary: The development of creativity-Ability, motivation, and potential. In New Directions for Child. and Adolescent Development; Wiley-Blackwell Publishing: Hoboken, NJ, USA, 2016; pp. 111-119. [CrossRef] 
25. Feist, G.J. The function of personality in creativity. In The Cambridge Handbook of Creativity; Kaufman, J.C., Sternberg, R.J., Eds.; Cambridge University Press: Cambridge, UK, 2010; pp. 113-130. [CrossRef]

26. Feist, G.J. A meta-analysis of personality in scientific and artistic creativity. Pers. Soc. Psychol. Rev. 1998, 2, 290-309. [CrossRef]

27. Nijstad, B.A.; De Dreu, C.K.W.; Rietzschel, E.F.; Baas, M. The dual pathway to creativity model: Creative ideation as a function of flexibility and persistence. Eur. Rev. Soc. Psychol. 2010, 21, 34-77. [CrossRef]

28. Piffer, D. Can creativity be measured? An attempt to clarify the notion of creativity and general directions for future research. Think. Ski. Creat. 2012, 7, 258-264. [CrossRef]

29. George, J.M.; Zhou, J. Understanding when bad moods foster creativity and good ones don't: The role of context and clarity of feelings. J. Appl. Psychol. 2002, 87, 687-697. [CrossRef] [PubMed]

30. Guastello, S.J.; Guastello, D.D.; Hanson, C.A. Creativity, mood disorders, and emotional intelligence. J. Creat. Behav. 2004, 38, 260-281. [CrossRef]

31. Ivcevic, Z.; Brackett, M.A.; Mayer, J.D. Emotional intelligence and emotional creativity. J. Pers. 2007, 75, 199-236. [CrossRef] [PubMed]

32. Ivcevic, Z.; Hoffmann, J.D.; Brackett, M.A.; Botin, F. Emotions, Creativity, and the arts. In Arts and Emotions: Nurturing Our Creative Potential; Heys, B., Ed.; Fundación Botín: Santander, Spain, 2014; pp. 6-23. Available online: https://www.fundacionbotin.org/paginas-interiores-de-una-publicacion-de-la-fundacionbotin/artes-y-emociones-que-potencian-la-creatividad.html (accessed on 18 May 2020).

33. Guilford, J.P. Way Beyond the IQ; Creative Education Foundation: Buffalo, NY, USA, 1977; ISBN 0930222016.

34. Sánchez Hernández, Ó.; Méndez, F.X.; Garber, J. Producción divergente explicativa: La relación entre resiliencia y creatividad. Electron. J. Res. Educ. Psychol. 2017, 13. [CrossRef]

35. Kashdan, T.B.; Rottenberg, J. Psychological flexibility as a fundamental Aspect of health. Clin. Psychol. Rev. 2010, 30, 865-878. [CrossRef]

36. Cohen, J.B.; Andrade, E.B. Affective intuition and task-contingent affect regulation. J. Consum. Res. 2004, 31, 358-367. [CrossRef]

37. Fernández Berrocal, P.; Extremera Pacheco, N. La inteligencia emocional y la educación de las emociones desde el modelo de mayer y salovey. Rev. Interuniv. Form. Profr. 2005, 54, 63-94. Available online: www.redalyc.org/articulo.oa?id=27411927005 (accessed on 18 May 2020).

38. Shi, B.; Cao, X.; Chen, Q.; Zhuang, K.; Qiu, J. Different brain structures associated with artistic and scientific creativity: A voxel-based morphometry study. Sci. Rep. 2017, 7, 42911. [CrossRef]

39. Kuška, M.; Trnka, R.; Mana, J.; Nikolai, T. Emotional creativity: A meta-analysis and integrative review. Creat. Res. J. 2020. [CrossRef]

40. Averill, J.R. Individual differences in emotional creativity: Structure and correlates. J. Pers. 1999, 67, 331-371. [CrossRef]

41. Luke, D.; Zychowicz, K. Comparison of outcomes with nonintentional and intentional precognition tasks. J. Parapsychol. 2014, 78, 223-234.

42. Fuchs, G.L.; Kumar, V.K.; Porter, J. Emotional creativity, alexithymia, and styles of creativity. Creat. Res. J. 2007, 19, 233-245. [CrossRef]

43. Trnka, R.; Cabelkova, I.; Kuška, M.; Nikolai, T. Cognitive decline influences emotional creativity in the elderly. Creat. Res. J. 2019, 31, 93-101. [CrossRef]

44. Moltafet, G.; Sadati Firoozabadi, S.S.; Pour-Raisi, A. Parenting style, basic psychological needs, and emotional creativity: A path analysis. Creat. Res. J. 2018, 30, 187-194. [CrossRef]

45. Oriol, X.; Amutio, A.; Mendoza, M.; Da Costa, S.; Miranda, R. Emotional creativity as predictor of intrinsic motivation and academic engagement in university students: The mediating role of positive emotions. Front. Psychol. 2016, 7, 1243. [CrossRef] [PubMed]

46. Sordia, N.; Martskvishvili, K.; Neubauer, A. From creative potential to creative achievements. Swiss J. Psychol. 2019, 78, 115-123. [CrossRef] 
47. Rodríguez Hernández, A.F.; Nóbrega Carrión, B. Creatividad y Cambio Sociopersonal. Creat. Soc. Rev. Asoc. Creat. 2005, 8, 35-42. Available online: https://dialnet.unirioja.es/servlet/articulo? codigo $=2040642$ (accessed on 6 May 2020).

48. Extremera Pacheco, N.; Fernández Berrocal, P. La Inteligencia emocional: Métodos de evaluación en el aula. Rev. Iberoam. Educ. 2004, 34,1-12. [CrossRef]

(C) 2020 by the authors. Licensee MDPI, Basel, Switzerland. This article is an open access article distributed under the terms and conditions of the Creative Commons Attribution (CC BY) license (http://creativecommons.org/licenses/by/4.0/). 